\title{
Research on the machining process modeling of a rotational mold using CAM applications
}

\author{
Aurel Mihail Țîțu ${ }^{1,2^{*}}$, and Alina Bianca Pop ${ }^{3}$ \\ 1"Lucian Blaga" University of Sibiu, 10 Victoriei Street, Sibiu, România \\ ${ }^{2}$ The Academy of Romanian Scientists, 54 Splaiul Independenței, Sector 5, Bucharest, Romania, \\ ${ }^{3}$ Technical University of Cluj-Napoca, 62A Victor Babeș Street, Baia Mare, Romania
}

\begin{abstract}
Rotational molding is a unique process, with a high growth rate, which allows the use of geometries and materials adapted to particular needs. It is superior to other manufacturing methods in terms of low cost, break-even point and size of parts that can be manufactured. Rotational molding products are often a substitute, with a lower mass, for traditionally used materials. In this scientific paper it is analyzed the recent literature related to the field of rotational molding processes. It also addresses the issue of processing a rotational mold, with the main purpose of optimizing the cutting regime. In this context, it is highlighted the way of processing the surface of the outer mold based on deductions of direct observation criteria. The factors considered in this regard are the route, the type and diameter of the tool, the speed and depth of cutting - given that the goal is to achieve a minimum quality of the required surface obtained by technology and a minimum base time. At the end of the paper, the contribution of this research is highlighted along with the arguments presented in support of the statement that this rotational molding process is of particular interest because it has a great potential to meet many surface quality requirements, while reducing cycle times.
\end{abstract}

\section{Introduction}

Uniqueness of the rotational forming is found through a high growth rate, which allows to use geometries and materials that are adapted to specific needs [1].

The mold is essential in the rotational molding process [2]. Its main function is to define the final shape of the piece. The mold consists of four fundamental components without which the rotational molding process cannot be performed: cavity, support plate, frame and closing systems [3].

The molds used in the rotational molding process are generally made up of two parts: a main body and a lid. By closing the 2 component parts, a gap is formed inside the mold that mimics the shape of the part to be made [4]. The opening, on the other hand, allows the extraction of the finished part and the loading with raw material for a new cycle.

A particularity of the rotational molds is that when making the parts the pressure does not intervene but only the heat and a continuous rotation at a low speed $[5,6]$.

\footnotetext{
*Corresponding author: mihail.titu@ulbsibiu.ro
} 
By rotational molding the parts can be made in an economical way; the reason being the utilization coefficient of the material which is about $100 \%$, so there is no waste of raw material $[7,8]$.

The molds required for the rotational molding process can be obtained from several types of materials and can be made by several methods such as: aluminum molds obtained by casting or on numerically controlled machines, molds obtained from sheet metal thin steel and molds formed by EDM [9, 10]. A mold parametric design using CAD applications, involves to apply the following three basic steps - designing of [11]:

- The part shape and dimensions to be to be molded;

- The molds according to the part shape and dimensions;

- The fasteners of the rotating machine arm.

\section{Computer aided manufacturing of rotational molds}

Computer-aided manufacturing of rotational molds involves a set of computerized activities on the preparation, launch and monitoring of manufacturing. These activities include: tool management, materials management (semi-finished products, finished parts), manufacturing flow management, flexible manufacturing systems management and numerically controlled manufacturing processes management [12].

The concept of "Computer Numerical Control" (CNC) appeared around 1970, before that, the term used was NC, i.e. Numerical Control, the change was determined by the introduction of the computer in this process. CNC machines quickly took over much of the execution process that was performed on conventional machine tools, ensuring high productivity and accuracy. The operations performed on numerically controlled machines are very varied: milling, drilling, all turning operations, EDM, grinding, etc.

The elaboration of the manufacturing process of a part includes as phases: analysis of the shop floor drawing of the part, choosing the type of workpiece, establishing the process operations, structuring and ordering them, establishing the way of gripping the part, choosing machine tools, tools, devices and measuring instruments and controls, machining simulation, establishing the cutting regime and processing times, programming of machine tools with numerical control $[13,14]$.

The study of the different phases of elaboration of the processing process highlights two types of activities:

- creative activities: defining the way of working, choosing the technical means, choosing the technological solutions, choosing the best processing process;

- routine activities: determination of cutting regimes, calculation of times, preparation of technological shop floor documentation.

Computer Aided Process Planning (CAPP) allows the automatic establishment of a processing process starting from the geometric description of the workpiece [15].

A CAPP system must allow [16]:

- $\quad$ setting up an easily exploitable technological database, capable of presenting the available means and processing methods;

- choosing from all compatible solutions for performing a cost-minimizing solution operation;

- rationalization of manufacturing, based on the principles of group technology;

- facilitating staff training;

- reduction of repetitive works;

- reduction of manufacturing monitoring activities.

PowerMILL is a modern system based on technology and the most modern application development solutions. 
The calculation speed is impressive, PowerMILL calculates the toolpaths and stores all intermediate calculations for any subsequent changes. When the machine parameters change, the new tool path is generated almost instantly, without the need to recalculate it from the beginning, which allows the user to make a very large number of attempts to reach the optimal variant to obtain a quality part in as short a time as possible. With the help of the PS-Optifeed module, PowerMILL even shortens the working time of the machine by approximately $40 \%$ by optimizing the feed so that we have a constant load on the tool. Machine statistics can be automatically generated for each selected route, including estimates of milling time and tool path length. All this information together with all the other data required by the machine man is put in the technology sheet automatically generated by PowerMILL in HTML format. Geometric models can be imported into PowerMILL in a variety of ways, including standard format files IGES, VDA-FS, STL, STEP, Parasolid, or specific interfaces for certain assisted design solutions (PowerSHAPE, CADDS, Catia, ProEngineer, SolidWorks, Unigraphics,) to ensure a very good takeover of these models.

\section{Research design}

\subsection{Simulation methods using the CAM PowerMill application}

In principle, the efficient generation of the machining trajectory (tool trajectory) for $\mathrm{CNC}$ machining involves going through a logical sequence of steps such as:

- establishing the processing coordinate system;

- $\quad$ establishing the workpiece material;

- choosing the optimal tool;

- choosing the machining strategy;

- establishing the ways of engaging and retracting the tool in and out of the chip.

- simulation and trajectory validation.

The virtual generation of the trajectory is followed by the generation of the numerical control file and its transmission to the machine together with the technological documentation necessary for the human operator who serves the machine tool with numerical control. By way of 3D simulation, PowerMILL can check the toolpaths to prevent models collisions, in addition to afford this check for toolholders.

In addition, the user can simulate the shading processing path not only in the wireframe, using the real image of what will happen to the machine, PowerMILL ensures that what is seen through the simulation will happen exactly to the machine in reality.

At the same time, the simulation is useful in visualizing the directions of movement of the cutting tool, in order to estimate the point at which the cutting tool will reach a given moment. [17, 18].

Figure 1 shows a diagram with the links between the steps required to make a rotational mold using CAD and CAM tools.

In PowerMILL, the blank defines the area for generating the tool path. This way you can define the trajectories on the whole model or on its areas. The path generation limits are given by the condition that the tool axis is included inside the blank (unless the path is limited by other conditions, especially boundary curves). 


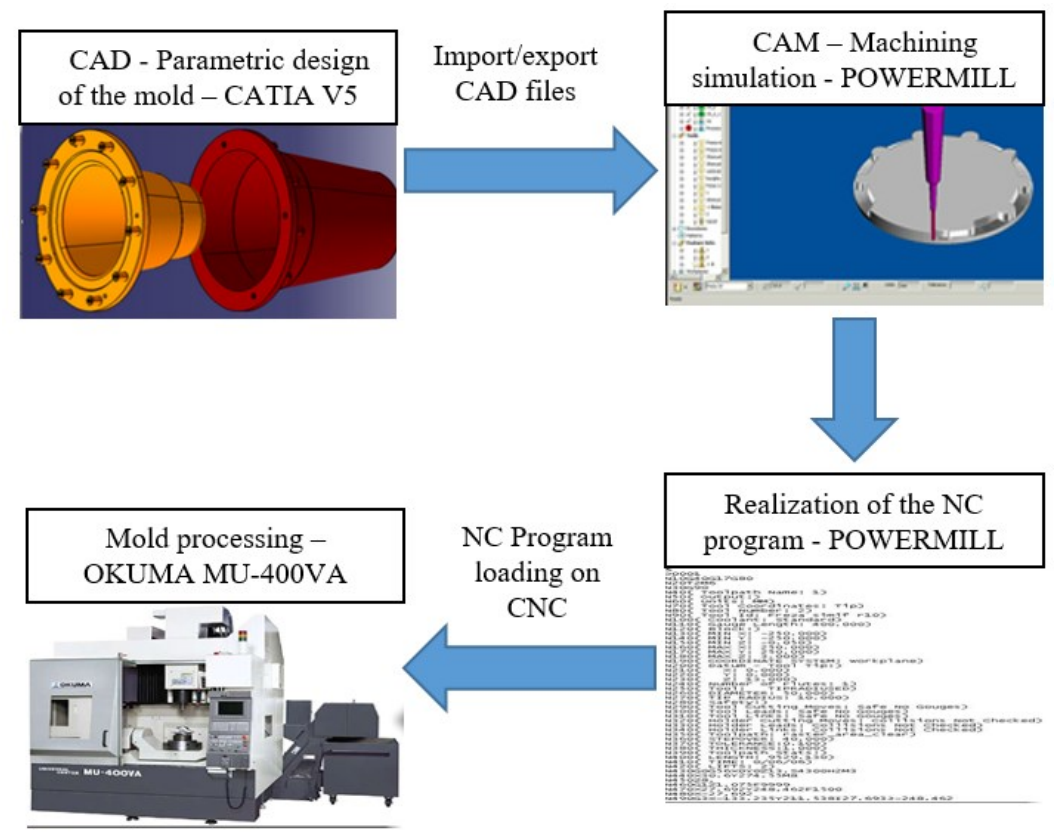

Fig. 1. The stages of creating the rotational mold [17].

\subsection{The cutting regime Optimization of using PowerMill CAM application}

This paper focused on the processing of an external die surface based on deductions based on direct observation criteria (tool path, cutting tool diameter and type, cutting speed and cutting depth) with the objectives of the best surface quality obtained by formation and minimum processing time. In this context, the aim was to optimize the cutting process.

In order to achieve this goal, a series of steps must be taken which will be discussed in the following.

In the first phase, the most suitable tool processing path was determined, so that the basic time is minimal.

Below are the input data related to the studies for the analyzed cases, including the cutting tool and the cutting regimes adopted. The starting point is the toolpath set by the PowerMill application, as follows:

\subsubsection{The Raster AreaClear Model route}

Using this path, the tool made a zig-zag movement, as can be seen in Figure 2, processing the blank by milling till it meets the surface of the part previously loaded into the program (Fig. 3). 


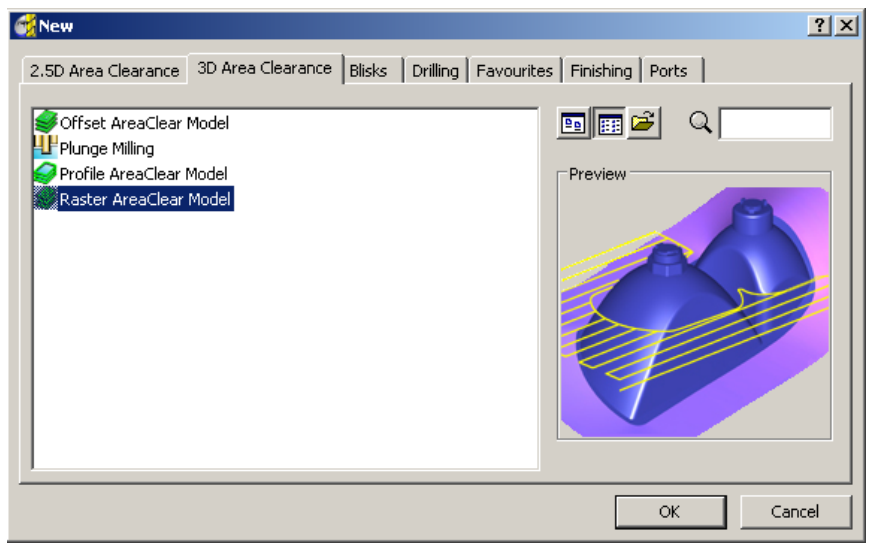

Fig. 2. The Raster AreaClear Model route.
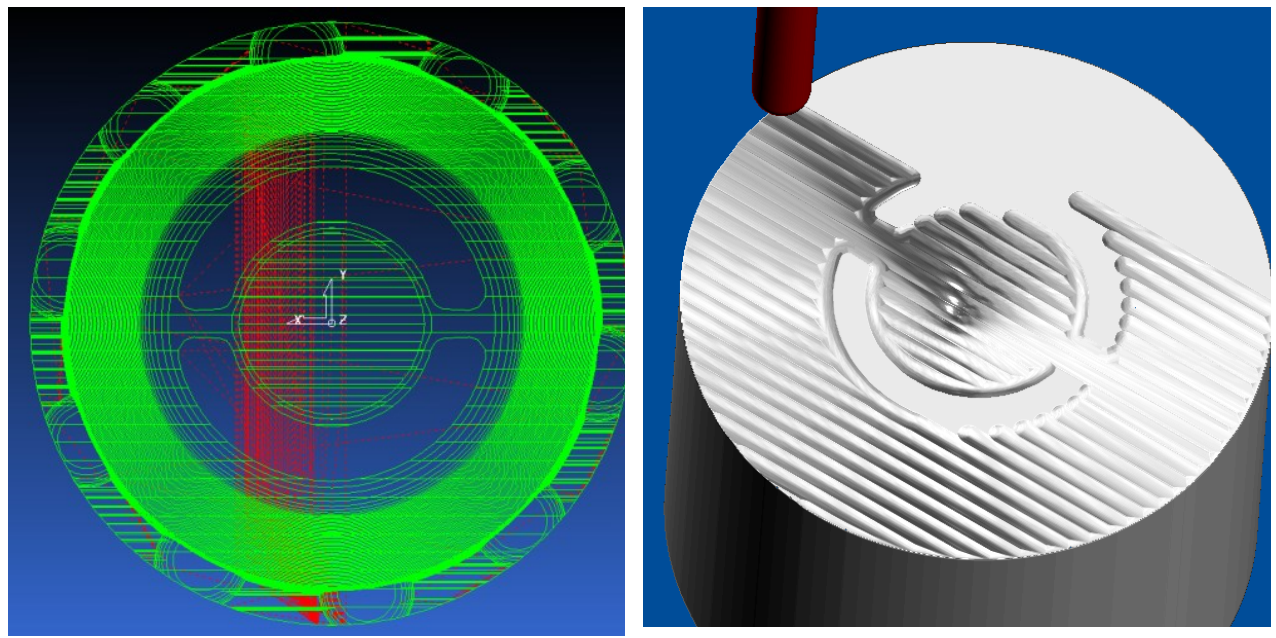

Fig. 3. Tool paths.

Once the tool comes into contact with the workpiece, it does not leave it until the machining is completed. At the end of a working trajectory there is a movement in the positioning direction, until the position is established for the next passage [17].

Table 1. The Raster AreaClear Model route -Tool: SECO R218.20-2.0050.3P-70.120.

\begin{tabular}{|c|c|c|}
\hline \multicolumn{3}{|c|}{ Cutting depth $\mathrm{A}_{\mathrm{p}}[\mathrm{mm}]$} \\
\hline 4 & 10 & 15 \\
\hline \multicolumn{3}{|c|}{ Roughness calculation $R_{a}=\frac{H}{4}[\mu \mathrm{m}]$} \\
\hline 20 & 132.5 & 302.5 \\
\hline
\end{tabular}

Graphical representation - Measurement the asperities using the parametric criteria of CATIAV5 - 




\subsubsection{AreaClear Model Offset Route}

In the Offset Model AreaClear route (figure 4), by the machining movement performed by the tool, it remains permanently in contact with the workpiece, similar to the zig-zag machining strategy, the difference is the lack of positioning movement for the next pass, this being transformed into a working movement depending on the positioning direction.

The result is an approximately spiral motion on the surface of the part. The direction of movement can be from outside to inside or from inside to outside (figure 5). 


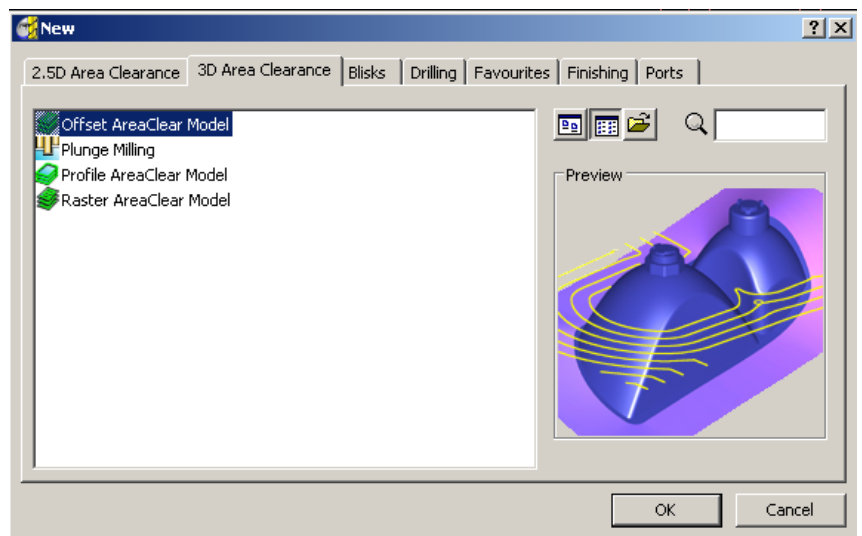

Fig. 4. AreaClear Model Offset Route.
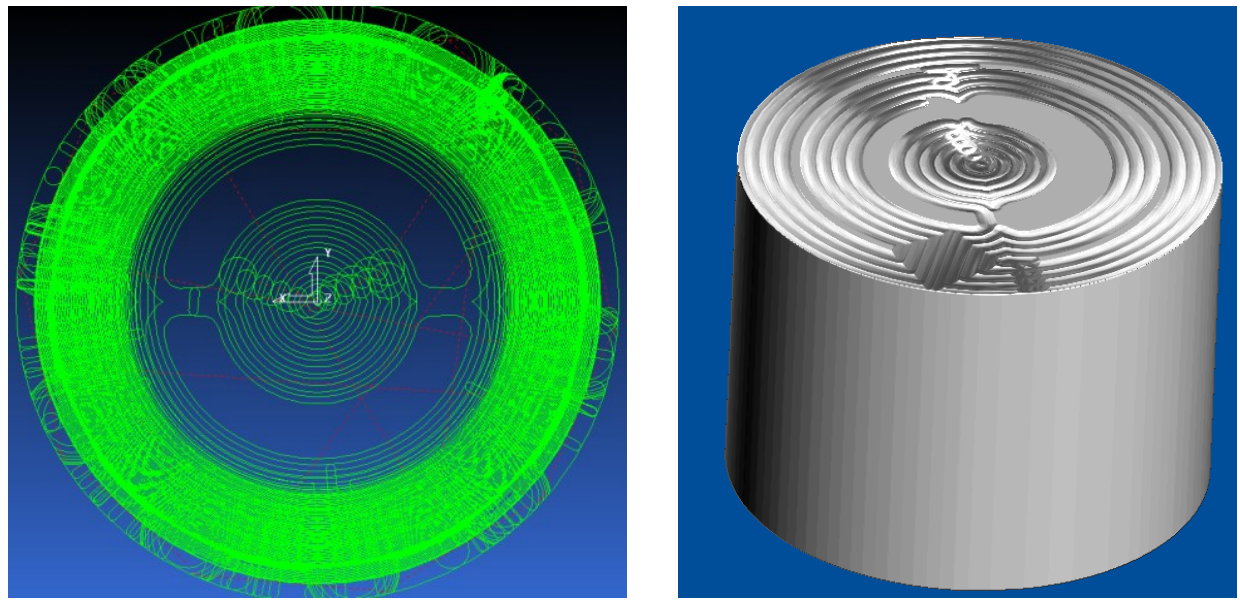

Fig. 5. Tool paths.

Due to the fact that the cutting process runs smoothly, the choice of this Offset AreaClear Model route ensures maximum productivity - and the processing time is minimal (table 2).

Table 2. AreaClear Model Offset Route - Tool: SECO R218.20-2.0050.3P-70.120.

\begin{tabular}{|c|c|c|}
\hline \multicolumn{3}{|c|}{ Cutting depth $\mathrm{A}_{\mathrm{p}}[\mathrm{mm}]$} \\
\hline 4 & 10 & 15 \\
\hline \multicolumn{3}{|c|}{ Roughness calculation $R_{a}=\frac{H}{4}[\mu \mathrm{m}]$} \\
\hline 20 & 132,5 & 302.5 \\
\hline Graphical representation - Measurement the asperities using the parametric criteria of CATIAV5 - \\
$2 \mathrm{D}$
\end{tabular}




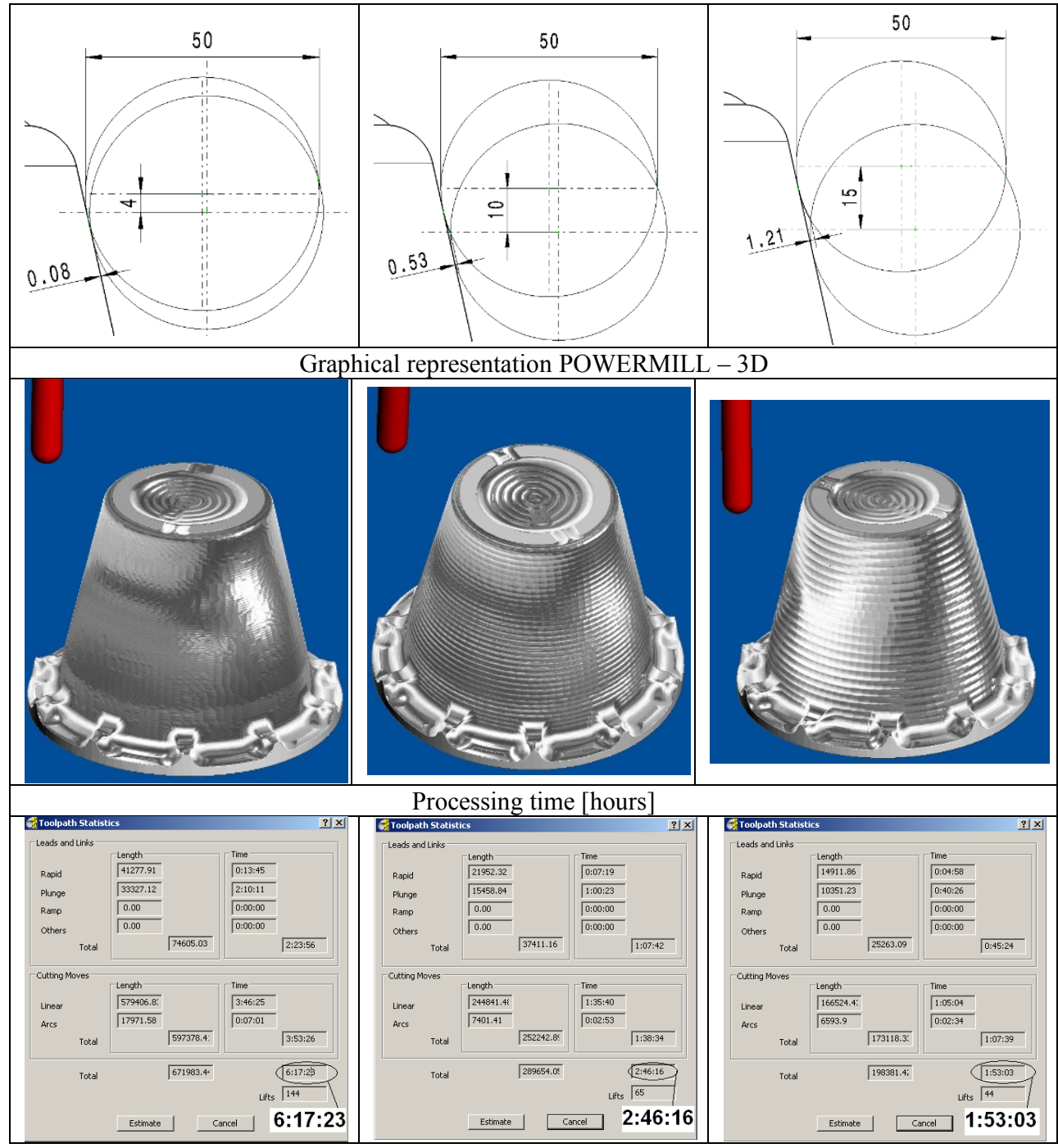

The choice of the optimal processing strategy solves the problem of the basic time determining the minimum, but the situation of the minimum roughness is not conclusive, at the two routes remaining unchanged (figure 6).

In order to solve this impediment, in the following two more cases will be presented in which, keeping the processing route (the one that turned out to be optimal) of the tool and the cutting depths, the differentiation will be only when choosing the tools. 


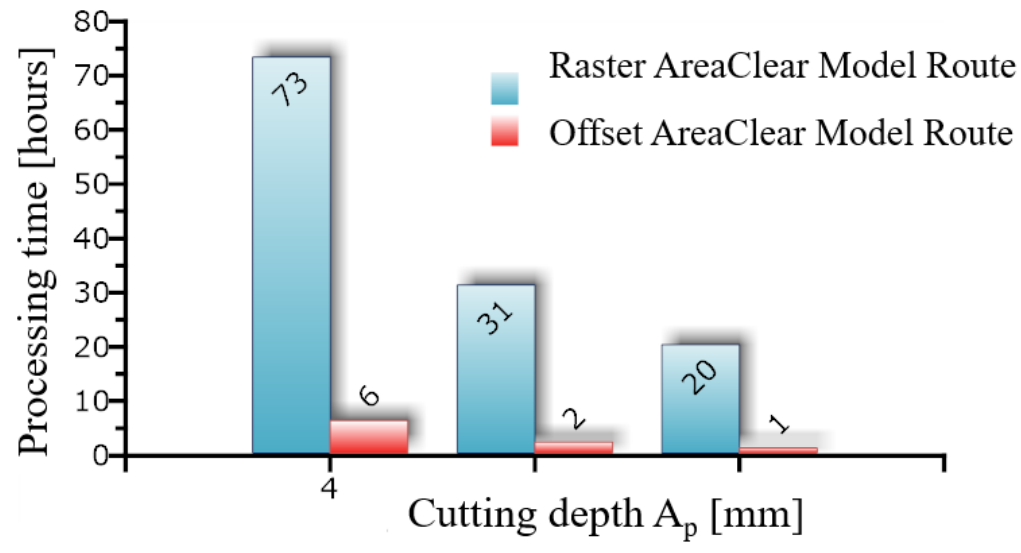

Fig. 6. Variation of machining time depending on the cutting depth and the machining path of the tool.

Next, the condition of the outer surface (roughness) of the outer half-mold and the change of the working time (surface number 7) will be monitored. For the calculation of the roughness, the formula from figure 7 will be used, where $\mathrm{H}$ represents the height of the irregularity and $\mathrm{A}_{\mathrm{p}}$ - the radial cutting depth.

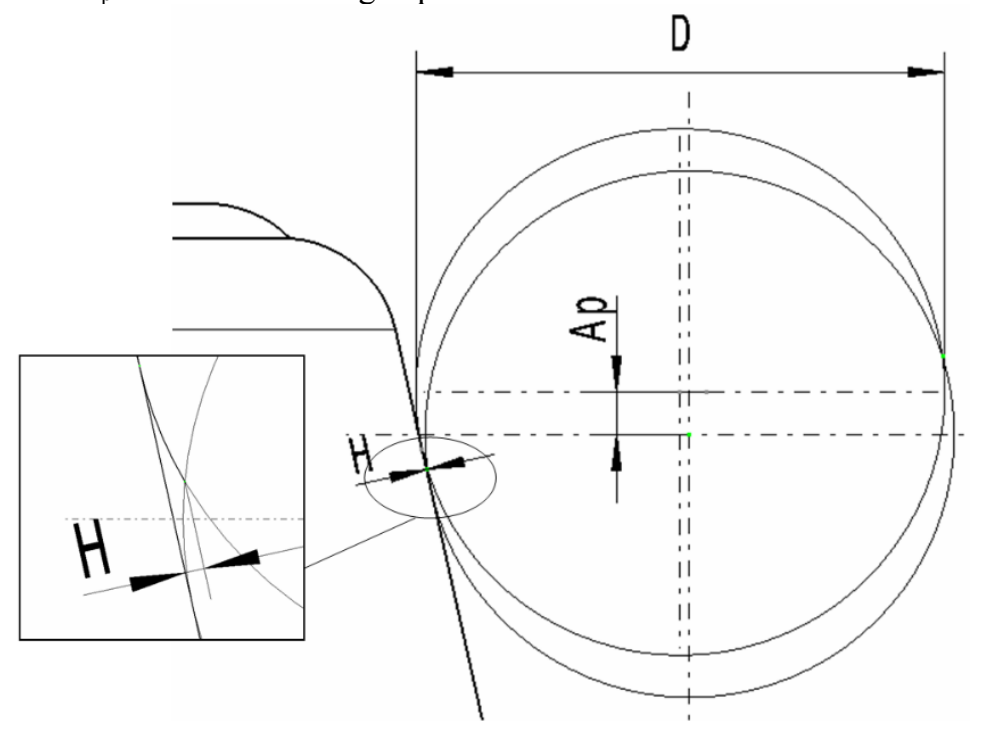

Fig. 7. Measurement of the height of the irregularities on the outer surface of the mold.

Therefore, the situations are as follows (table 3):

Table 3. Choosing the tools types

\begin{tabular}{|c|c|c|c|c|c|c|}
\hline Case & Tool type & $\begin{array}{c}\text { Tool diameter } \\
\mathrm{D}[\mathrm{mm}]\end{array}$ & $\begin{array}{c}\text { Cutting speed } \\
\mathbf{V}_{\mathrm{c}}[\mathrm{m} / \mathrm{min}]\end{array}$ & \multicolumn{3}{|c|}{$\begin{array}{c}\text { Cutting depth } \\
\mathbf{A}_{\mathbf{p}}[\mathbf{m m}]\end{array}$} \\
\hline 1 & R218.20-2.0050.3P-70.120 & 50 & 670 & \multirow{3}{*}{4} & \multirow{3}{*}{10} & \multirow{3}{*}{15} \\
\hline 2 & R218.20-3232.3-54.100A & 32 & 785 & & & \\
\hline 3 & R218.20-2525.3-45.080A & 25 & 785 & & & \\
\hline
\end{tabular}


Table 4. Offset AreaClear Model Route - Tool: SECO R218.20-3232.3-54.100A.

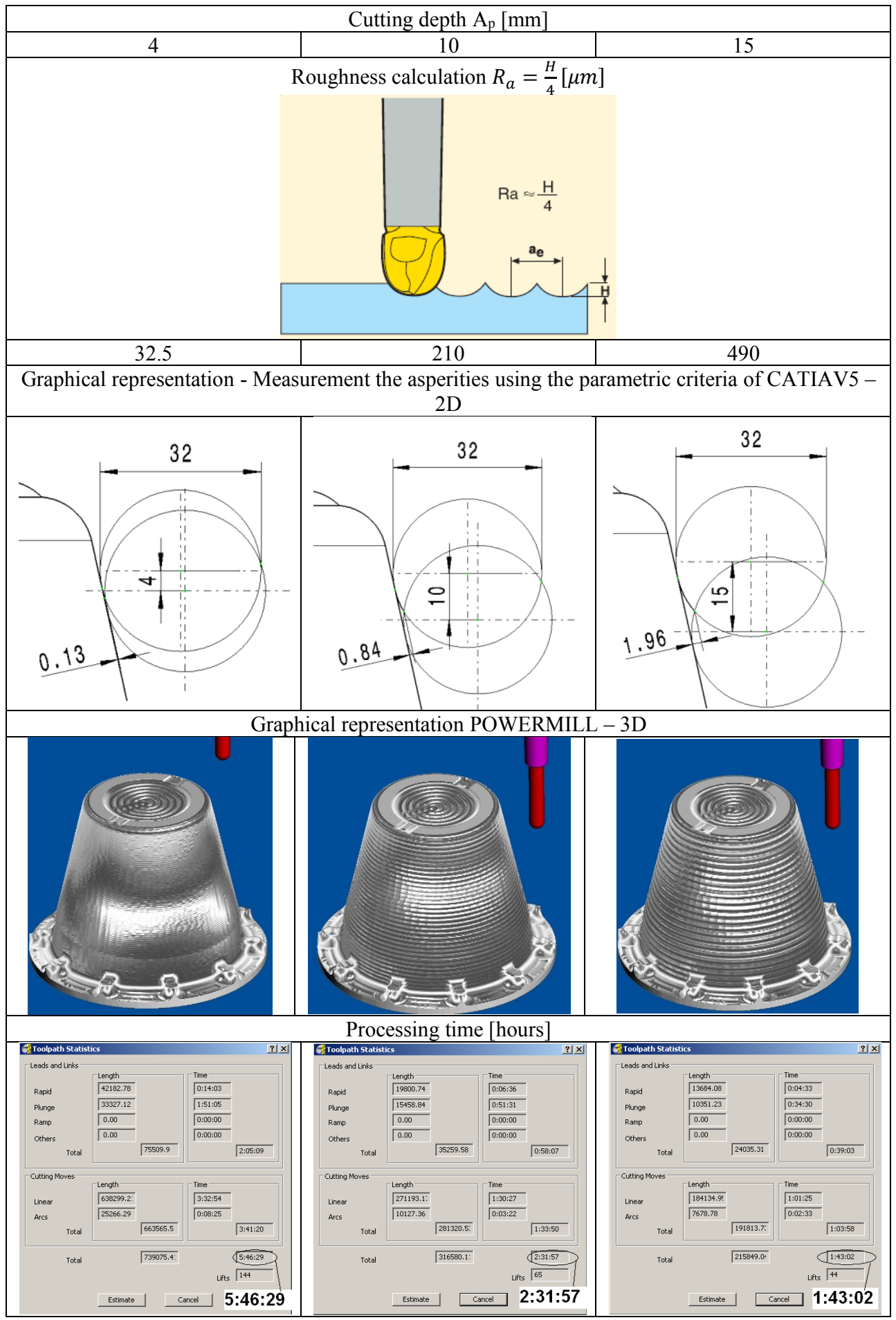


As can be seen in Tables 4 and 5, the larger the diameter of the cutter is, at the same cutting depth, the lower is the height of the surface irregularities, resulting in a lower roughness. In this case, based on the study, it was concluded that, in order to obtain a roughness as close as possible to $R_{a}=25[\mu \mathrm{m}]$, and a processing time as short as possible, the spherical milling cutter with diameter $\mathrm{D}=50[\mathrm{~mm}]$ and cutting depth $A_{p}=4[\mathrm{~mm}]$ will be used.

Both the value of $490 \mu \mathrm{m}$ and the value of $660 \mu \mathrm{m}$ are very high values of roughness. Precisely in this sense, the comparative study was performed in order to determine the optimal route for obtaining the lowest roughness. The study itself highlights this aspect.

Table 5. Offset AreaClear Model Route - Tool: SECO R218.20-2525.3-45.080A.

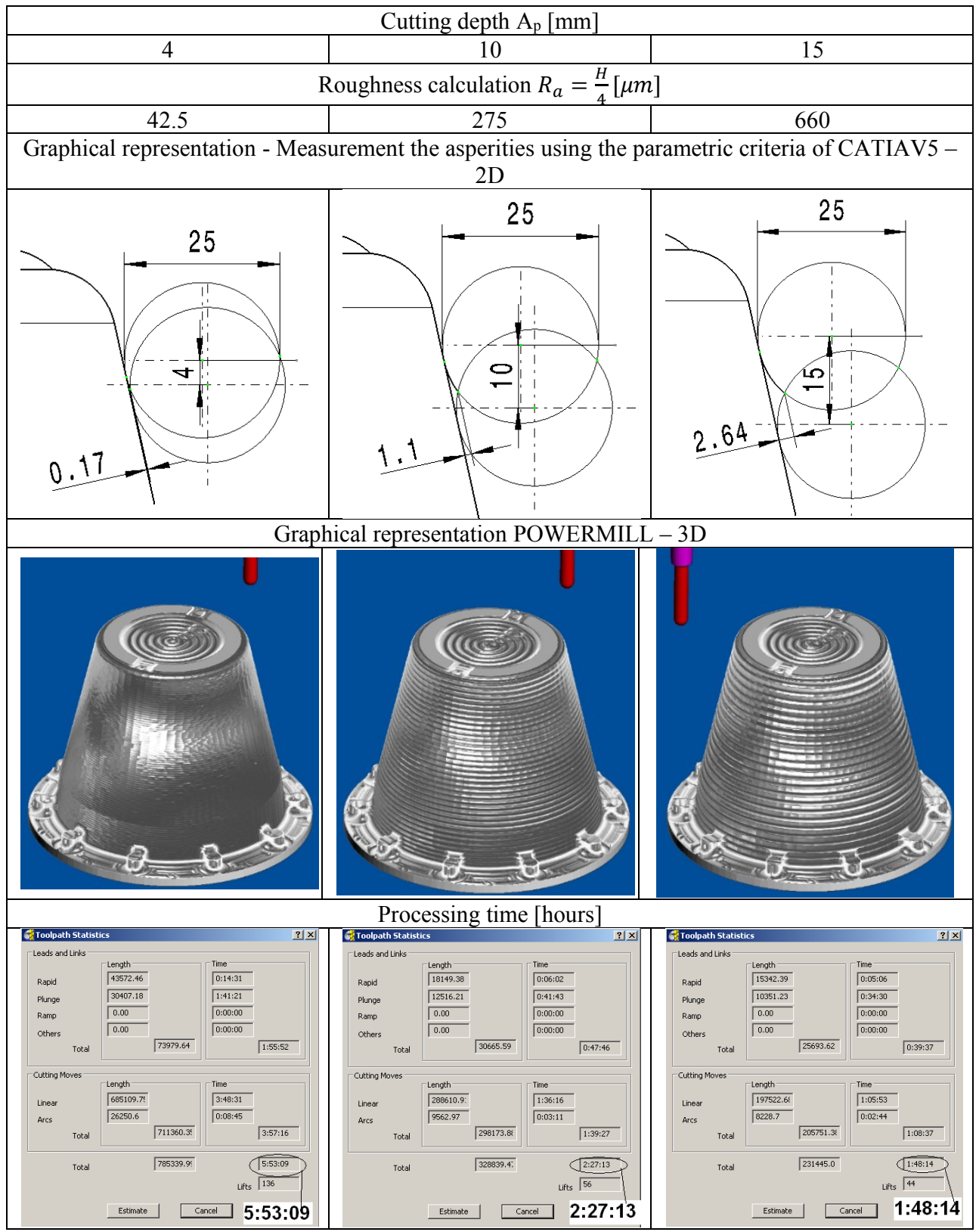




\section{CONCLUSIONS}

It can be said that today there is no branch of technology that does not benefit from the discoveries and research that led to the production of polymers and on this basis of plastics.

Plastics have solved some of the most important problems for cutting-edge fields of technology: in aerospace, electrical and electronic constructions (insulators of electrical conductors).

Plastics are used, with few exceptions, in all areas of activity. The specific molds for making hollow or partially hollow plastic parts are the rotational ones. Although the concept of rotational molding is older than 150 years, the production of plastic hollow parts for various has been used only for the last 50 years. Since the 1990s, the production of rotary molds at the industrial level has increased each year by between 10 and $15 \%$ [19].

The rotational molding process is unique, with a high growth rate, which allows the use of geometries and materials adapted to particular needs. Rotational molding is superior to other forming processes in terms of low cost, break-even point and size of parts that can be manufactured. Products made by rotational molding are often a substitute, with a lower mass, for traditionally used materials. This process involves the use of heat to melt and melt a plastic material in a closed mold. Unlike other plastics, pressure is not used. This process comprises three steps: loading the raw material into the mold, melting and fusing it, cooling and unloading the mold.

\section{References}

1. D. R. Yao Dou, Cell. Polym. 37, 55-68 (2017)

2. E. O. Cisneros-López, A. A. Pérez-Fonseca, Y. González-García, D. E. RamírezArreola, R. González-Núñez, D. Rodrigue, J. R. Robledo-Ortíz, Adv. Polym. Technol. 37, 2528-2540 (2018)

3. H. T. Nguyen, B. Cosson, M. F. Lacrampe, P. Krawczak, Int. J. of Mat. Forming, 8, 423438 (2015)

4. S. Sarrabi, M-F. Lacrampe, P. Krawczak, J. of App. Polymer Sc., 132, 41285/141285/11 (2014)

5. M. D. Monzón, P. Bordón, A. N. Benítez, M. Kearns, P. M. Hernández, M. D. Marrero, Polymer Engineering and Science, 52, 1998-2005 (2012)

6. N. Singh, D. Hui, R. Singh, I. P. S. Ahuja, L. Feo, F. Fraternali, Compos. Part B Eng. 115, 409-422, (2017)

7. A. Vignali, S. Iannace, G. Falcone, R. Utzeri, P. Stagnaro, F. Bertini, Polymers (Basel), 11, 624 (2019)

8. A. Greco, F. Ferrari, M.G. Buccoliero, G. Trono, Polymers (Basel), 11, 528 (2019)

9. F. J. Moscoso-Sánchez, E. Mendizábal, C. F. Jasso-Gastinel, P. Ortega-Gudiño, J. R. Robledo-Ortíz, R. González-Núñez, D. Rodrigue, J. Cell. Plast. 51, 489-503 (2015)

10. K. Ogila, M. Shao, W. Yang, J. Tan, Express Polym. Lett. 11, 778-798 (2017)

11. A. Vignali, S. Iannace, G. Falcone, R. Utzeri, P. Stagnaro, F. Bertini, Polymers, 11, 624 (2019)

12. J. R. Robledo-Ortíz, M. E. González-López, D. Rodrigue, J. F. Gutiérrez-Ruiz, F. Prezas-Lara, A. A. Pérez-Fonseca, J. Polym. Environ., 28, 1040-1049 (2020)

13. F. E. Hanana, C. Y. Desire, D. Rodrigue, Polym. Polym. Compos. 26, 299-307 (2018)

14. F. E. Hanana, D. Rodrigue, Curr. Appl. Polym. Sci. 2, 27-36 (2018)

15. R. C. Vázquez Fletes, E. O. Cisneros López, F. J. Moscoso Sánchez, E. Mendizábal, R. González Núñez, D. Rodrigue, P. Ortega Gudiño, Polymers, 12, 503 (2020)

16. G. Drăghici, The First International Symposium on Concurrent Enterprising, Integrated Approach in Computer Aided Process Planning, (Sinaia, Romania, 1998) 
17. A. B. Pop, G. I. Pop, A. M. Țîțu, MATEC Web of Conference, The Design and the Process Technology of a Rotational Mold, (Cluj Nacoca, Romania, 2019)

18. M. A. Țîțu, A. B. Pop, A Comparative Analysis of the Machined Surfaces Quality of an Aluminum Alloy According to the Cutting Speed and Cutting Depth Variations. In: Karabegović I. (eds) New Technologies, Development and Application II. NT 2019. Lecture Notes in Networks and Systems, (Springer, 2020)

19. R. J. Crawford, J. L. Throne, Rotational Molding Technology, (Plastics Design Library/William Andrew Publishing, USA, 2002) 